\title{
CORRECTIONS
}

\section{Don't ignore home grown medical systems}

The surname of the third author listed in this Feature (BMJ 2010;340:c3187, doi:10.1136/bmj.c3187) has been spelt incorrectly. The author's full name should have read Joia Mukherjee [not "Mukharjee" as was published].
Cite this as: BMJ 2015;350:h3495

๑ BMJ Publishing Group Ltd 2015 